\title{
FACULTY SELECTION FOR A BRAZILIAN PRIVATE HIGHER EDUCATION INSTITUTION
}

\author{
Valério A. P. Salomon* \\ São Paulo State University \\ Guaratinguetá, SP, Brazil \\ E-mail: salomon@feg.unesp.br \\ Fábio Soares Duarte \\ Centro das Indústrias do Estado de São Paulo \\ Taubaté, SP, Brazil \\ E-mail: fabiosoaresduarte@gmail.com \\ José Lourenço Junior \\ Centro das Indústrias do Estado de São Paulo \\ Taubaté, SP, Brazil \\ E-mail: jose.lourenco@pinha.com.br \\ Norival de Paula \\ Centro Universitário Salesiano de São Paulo \\ Lorena, SP, Brazil \\ E-mail:norival@lo.unisal.br
}

\begin{abstract}
The purpose of this work is, starting from a practical case of faculty selection for a higher education institution, to present and to examine the subjective selection method commonly used by private educational institutions in Brazil. In addition, it shows how the results would have been if the AHP had been applied. Furthermore, a comparison will be made between the usages of both methods. The main objective of the selection process is to approve candidates who combine knowledge, skills and ability to efficiently develop their function in the institution. Mistakes in this process can lead to waste of time, money and other resources. Therefore, attributes like didactics and resourcefulness in the classroom gain relevance, while replaces traditional attributes, such as academic background.
\end{abstract}

Keywords: Higher education, Personnel selection.

\section{Introduction}

The goal of a faculty selection process is to choice of candidates who have knowledge, skills and capabilities needed to perform efficiently and effectively his or her function within organization. Moreover, according to Avelar et al. (2003), this selection shall take in to consideration the adherence of individual values to those recognized by the HEI (Higher Education Institution).

The faculty selection is a process with long term effect in the HEI's capability to fulfill its mission (Grandzol, 2005). This process influences the quality of teaching, the effectiveness of the HEI's programs and activities, and its financial efficiency. Failures in this process, such as the choice of an inadequate

* Corresponding author 
candidate, may result in waste of time and unnecessary spending. "Hiring the wrong person may lead to dysfunctional departments, dissatisfied students, and, eventually, repeat efforts."

According to Deming (1986), "Western style of management must change to halt the decline of Western industry, and to turn it upward. There must be awakening to the crisis, followed by action-management's job. The transformation can only be accomplished by man, not by hardware (computers, gadgets, automation, and new machinery). A company cannot buy its way into quality". Education, particularly the Higher Education, is headed towards a commercial competition. Redmond et al. (2008) has identified shortcomings of HEI as poor teaching, anachronistic programs, incoherent curricula, excessive price, and growing in inefficient administrative bureaucracies.

Brazilian public HEIs have a systematic way of performing the faculty selection, named as public contest. However, Brazilian private institutions prefer to select their professors based on personal indication, interviews or even the observation of the candidate acting in classrooms (Avelar et al., 2003). Consequently, attributes like didactics and resourcefulness in the classroom gain relevance, replacing traditional attributes like academic background.

The purpose of this work is, starting from a practical case of faculty selection for an HEI, to present and to examine the subjective selection method commonly used by private educational institutions in Brazil. It also shows how the results would have been if the AHP (Analytic Hierarchy Process) had been applied. This way, an ex-post facto approach was taken in this work. It is also important to mention that two of this paper's authors were directly involved in the application of both the subject and the AHP methods. A comparison between the results derived from both methods is also presented.

\section{The practical case of faculty selection}

Paraiba Valley is the geographical region located between Sao Paulo City and Rio de Janeiro City. It is one of the most prominent regions of the country and has an industrial vocation. This work presents a real case that took place at a small private HEI located in Sao Paulo State's part of Paraiba Valley. Currently, this institution has 10 courses in Biomedical, Human and Social Sciences. There were 1,500 enrolled undergraduate students in 2008. The HEI employs around 200 workers, including professors and administrative personnel.

The faculty selection process is for the Logistics discipline which is part of the BA (Business Administration) course. First of all, an internal search for capable professors was performed within the HEI. However, there was no available professor with the required qualifications in that area. As a result, a board of three professors from the BA course was formed. This board had the responsibility to indicate possible candidates and to select one for this discipline. No public announcing was performed, except by the professors' network outside of to the HEI. 20 resumes were received and the board of professors preselected six candidates.

Each one of the six candidates performed each one a 20-minutes test-lesson of professors. After these lessons, their resumes were re-evaluated, but with a closer attention do it. In regards to this evaluation, it is important to mention the attributes that were considered. The first is concerned with costs. According to the HEI's policies, a professor holding a master's degree has a salary $47 \%$ higher than one with a bachelor's degree only. In addition, a professor with a doctor's degree earns $18 \%$ more than another with a master's degree only. On the other hand, both the institution and the BA course have already been successfully evaluated by the state and federal government education agencies. There is no need to seek for faculty with higher academic background. Therefore, the cost attribute shows that there was a preference for a professor with a lower academic background. Another interesting point regarding the cost 
deals with the candidate's home town. The HEI does not intend to provide its employees with the transportation costs. As a result, it was important to select a professor who lives near the institution. The candidate's mobility will be an important factor when class schedule changes or substitutions in the lessons occur. Also, by having lower transportation costs, the candidates may feel more attracted by the same wage. Other attributes, such as knowledge and experience in Logistics, experience in other areas, academic experience, and publications over the last three years were also considered.

After the entire evaluation is performed, the board of professors indicates one candidate to the HEI's Dean. In this case, Candidate 3 was chosen by the board. The Dean confirmed this decision.

\section{Analytic Hierarchy Process application}

MCDM (Multiple-Criteria Decision-Making) is the study of the inclusion of conflicting criteria in decision-making, as defined by the International Society on MCDM (2008). A survey by Salomon \& Shimizu (2006) shows that the AHP is one of the MCDM methods most applied to solve practical problems in Brazil. The AHP was introduced by Saaty (1977 and 1980). Saaty (2006) presents the theory on which the method is based on and also many of its applications.

Table 1 presents an attributes hierarchy and the weights that were obtained from pairwise comparisons performed by two of the three professors involved in the practical case presented in Section 2. The same set of attributes was considered as previously. As it can be seen academic background was considered to be the least important attribute, while the candidate's previous experience was the most important one.

Table 1 . Hierarchy for the attributes for the faculty selection.

\begin{tabular}{|c|c|c|c|c|c|c|c|c|c|}
\hline \multicolumn{4}{|c|}{$\begin{array}{c}\text { Earlier Career } \\
26 \%\end{array}$} & \multicolumn{2}{|c|}{$\begin{array}{c}\text { Didactics } \\
18 \%\end{array}$} & \multicolumn{2}{|c|}{$\begin{array}{c}\text { Costs } \\
45 \%\end{array}$} & \multicolumn{2}{|c|}{$\begin{array}{c}\text { Background } \\
11 \% \\
\end{array}$} \\
\hline \multicolumn{2}{|c|}{$\begin{array}{c}\text { Higher Education } \\
75 \%\end{array}$} & \multicolumn{2}{|c|}{$\begin{array}{l}\text { Other } \\
25 \%\end{array}$} & \multirow[t]{2}{*}{$\begin{array}{c}\text { Test-lesson } \\
75 \%\end{array}$} & \multirow[t]{2}{*}{$\begin{array}{c}\mathrm{DE} \\
25 \%\end{array}$} & \multirow[t]{2}{*}{$\begin{array}{c}\text { Background } \\
75 \%\end{array}$} & \multirow[t]{2}{*}{$\begin{array}{l}\text { Home } \\
25 \%\end{array}$} & \multirow[t]{2}{*}{$\begin{array}{c}\text { Logistics } \\
50 \%\end{array}$} & \multirow[t]{2}{*}{$\begin{array}{c}\text { Publications } \\
50 \%\end{array}$} \\
\hline $\begin{array}{c}\text { Logistics } \\
75 \%\end{array}$ & $\begin{array}{l}\text { Other } \\
25 \%\end{array}$ & $\begin{array}{c}\text { Logistics } \\
75 \%\end{array}$ & $\begin{array}{l}\text { Other } \\
25 \%\end{array}$ & & & & & & \\
\hline
\end{tabular}

Table 1 also shows that that academic background appears both in the first level (usually named as criteria level) and in the second level (as a sub-criterion for Costs). This observation was, in fact, explained in Section 2. Another interesting point is the presence of the DE (Distant Education) as a subcriterion for Didactics. In this attribute, the candidate's ability and familiarity with DE techniques, such as web-conferencing, was measured. This attribute was implicitly considered in the practical case, but not for every candidate.

Table 2 presents the Decision Matrix for the faculty selection. With the exception of the values for Costs, all the candidates' performances were obtained with pairwise comparison. As previously mentioned in Section 2, numeric data has been made available in regards to the costs associated with every candidate. Candidate 6 had the higher value since he has only a bachelor degree and he lives in the HEI's town. 
Table 2. Performances of the candidates

\begin{tabular}{|c|c|c|c|c|}
\cline { 2 - 5 } \multicolumn{1}{c|}{} & Earlier Career & Didactics & Costs & Background \\
\hline Candidate 1 & $27 \%$ & $17 \%$ & $11 \%$ & $38 \%$ \\
\hline Candidate 2 & $23 \%$ & $17 \%$ & $11 \%$ & $24 \%$ \\
\hline Candidate 3 & $25 \%$ & $26 \%$ & $23 \%$ & $14 \%$ \\
\hline Candidate 4 & $11 \%$ & $16 \%$ & $11 \%$ & $6 \%$ \\
\hline Candidate 5 & $5 \%$ & $17 \%$ & $17 \%$ & $10 \%$ \\
\hline Candidate 6 & $9 \%$ & $8 \%$ & $28 \%$ & $7 \%$ \\
\hline
\end{tabular}

The judgments on the candidates' performance according to every attribute were provided by the same two professors who performed the judgments for the weights showed in Table 1. Even though it was the first time the AHP was being applied by those professors, none of the judgment matrices showed an inconsistency ratio higher than the $10 \%$ limit proposed by Saaty (2006). This factor implies in a higher confidence on the method perceived by the professors. And also implies in a higher confidence in the values they are inputting in the decision process.

Table 3 presents the Decision Vector for the faculty selection. It can be seen that Candidate 3 has the higher overall performance with $23 \%$. Therefore, it can be stated that the subject method adopted for faculty selection presented in Section 2 and the AHP application have the same result.

Table 3. Overall performances of the candidates

\begin{tabular}{|l|c|}
\cline { 2 - 2 } \multicolumn{1}{c|}{} & Overall performance \\
\hline Candidate 1 & $19 \%$ \\
\hline Candidate 2 & $16 \%$ \\
\hline Candidate 3 & $23 \%$ \\
\hline Candidate 4 & $12 \%$ \\
\hline Candidate 5 & $13 \%$ \\
\hline Candidate 6 & $17 \%$ \\
\hline
\end{tabular}

\section{Conclusions}

When the selection process is not properly performed, many difficulties may arise in an organization. The choice of one person, i.e. a professor, without an adequate profile and not meeting the minimum requirements for a good performance, will generate many frustrations for the HEI and for the selected person him/herself. In order to be efficient, the selection process shall reduce the need for resources and shall contemplate the real needs and preferences of the HEI. To be effective, the selection process shall result in the choice of candidates who are really qualified for their functions.

In this work, the selection process performed in the conventional way has selected the same candidate as the AHP application. It was conducted an ex-post facto approach for the AHP application. However, there was a short lack of time and two of the three professors who acted as decision makers in the first selection process also acted in the AHP application. They perceived that some attributes that were implicitly counted for only one candidate, were considered for all candidates when using the AHP application. This actually happened with the DE attribute. Even though the final results from both applications were basically the same (Candidate 3 was chosen), may argue that the AHP application may suggests that Candidate 1 should be the one considered. In fact, this result should be investigated with a sensitivity analysis of the Decision Vector (presented in Table 3) to the weights of the attributes (Table 1). 
Aside from of the successful AHP application the HEI is now facing another problem. The two professors who made the AHP application presented in this paper are the only ones who know the method within organization. In order to make the AHP the official method for faculty selection in the HEI, the two professors will be acting as knowledge multiplier. Since they have an Engineering background, the AHP algebra was not difficult for them. In fact the entire AHP application showed in this work was conducted with no specific software (Decision Lens, Expert Choice, Superdecisions etc.). They only used electronic spreadsheets. In order to make AHP the HEI standard method to faculty selection, the HEI has to decide if the professors will act as internal consultants or if it will be necessary to acquire specific software. However, these are decisions to be analyzed by another work.

\section{REFERENCES}

Avelar, L.P., Leitão, R.L.S.D., \& Martinez, A.M. (2003). Seleção de professores: uma experiência inovadora. Psicologia Escolar e Educacional.7 (2), 217-219.

Deming, W.E. (1986). Out of the Crisis. Cambridge: MIT Press.

Grandzol, J.R. (2005). Improving the Faculty Selection Process in Higher Education: A Case for the Analytic Hierarchy Process. IR Applications, 6, 1-13.

International Society on MCDM (2008). Introduction. http://www.mcdmsociety.org/intro.html, last updated in December 5 .

Redmond, R., Curtis, E., Noone, T., \& Keenan, P. (2008). Quality in higher education: The contribution of Edward Deming's principles. International Journal of Educational Management, 22 (5), 432-441.

Saaty, T.L. (1977). A scaling method for priorities in hierarchical structures. Journal of Mathematical Psychology. $15,234-281$.

Saaty, T.L. (1980). The Analytic Hierarchy Process. New York: McGraw-Hill.

Saaty, T.L. (2006). Fundamentals of Decision Making and Priority Theory with the Analytic Hierarchy Process. Pittsburgh: RWS Publications.

Salomon, V.A.P., \& Shimizu, T. (2006). Performance of three different methods of multiple criteria decision making applied to the supplier selection. International Conference on MCDM, 18, Chania, Greece. 